\title{
Myocardium at risk with contrast enhanced SSFP compared to myocardial perfusion SPECT Peder Sorensson*1, Einar Heiberg${ }^{2}$, Nawsad Saleh ${ }^{1}$, Frederic Bouvier ${ }^{1}$, Kenneth Caidahl ${ }^{1}$, Per Tornvall ${ }^{1}$, Lars Rydén ${ }^{1}$, John Pernow ${ }^{1}$ and Håkan Arheden ${ }^{2}$
}

Address: ${ }^{1}$ Karolinska Institutet, Stockholm, Sweden and ${ }^{2}$ Lund University, Lund, Sweden

* Corresponding author

from 13th Annual SCMR Scientific Sessions

Phoenix, AZ, USA. 21 -24 January 2010

Published: 21 January 2010

Journal of Cardiovascular Magnetic Resonance 2010, I2(SuppI I):PII9 doi:I0.I I86/I532-429X-I2-SI-PII9

This abstract is available from: http://jcmr-online.com/content/I2/SI/PII 9

(c) 2010 Sorensson et al; licensee BioMed Central Ltd.

\section{Introduction}

Final infarct size following coronary occlusion is determined by the duration of ischemia, the size of myocardium at risk $(\mathrm{MaR})$ and reperfusion injury. The reference method for determining MaR, single-photon emission computed tomography (SPECT) imaging before reperfusion, is impractical in an acute setting.

\section{Purpose}

The aim of the present study was to evaluate whether MaR can be determined from the contrast enhanced myocardium on steady-state free precession (SSFP) performed one week after the acute event in patients with ST-elevation myocardial infarction (STEMI).

\section{Methods}

Sixteen patients with STEMI (age $64 \pm 8$ years) received intravenous $99 \mathrm{~m}$-Tc immediately before primary percutaneous coronary intervention. A SPECT investigation was performed within four hours. MaR was defined as the non-perfused myocardial volume on SPECT. Magnetic resonance imaging (MRI) was performed $7.8 \pm 1.2$ days after the myocardial infarction using a protocol in which the contrast agent was administered before acquisition of short-axis cine images. MaR was evaluated as the contrast enhanced myocardial volume in cine SSFP by two blinded observers.

\section{Results}

MaR determined from the enhanced region on cine SSFP correlated significantly with that derived with SPECT $\left(\mathrm{r}^{2}=\right.$ $0.78, \mathrm{p}<0.001)$. The difference in MaR determined by $\mathrm{MRI}$ and SPECT was $0.5 \pm 5.1 \%($ mean $\pm \mathrm{SD})$. The interobserver variability of contrast enhanced cine SSFP measurements was $1.6 \pm 3.7 \%$ (mean $\pm \mathrm{SD}$ ) of the left ventricle wall volume Figures 1 and 2 .

\section{Conclusion}

This study suggests that contrast enhanced cine SSFP performed one week after reperfusion can serve as a novel imaging method to quantify MaR as it was before reperfusion. 
A

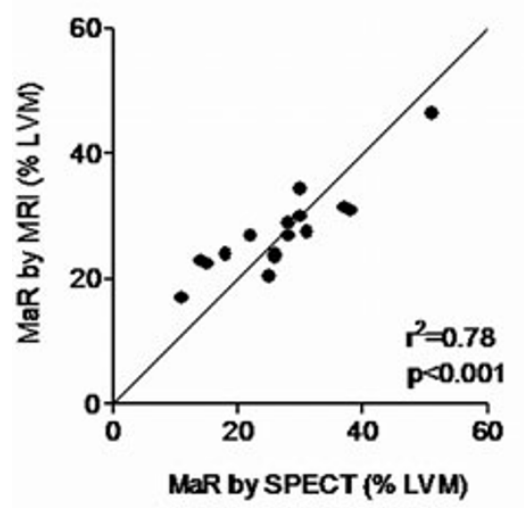

B

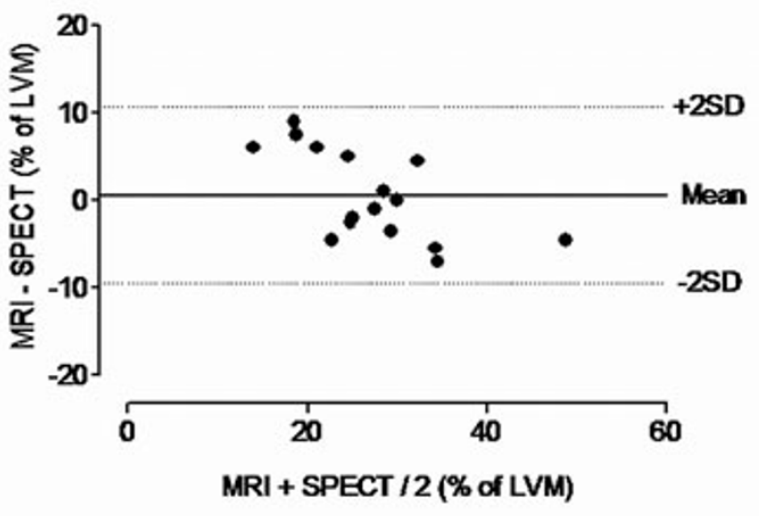

Figure I

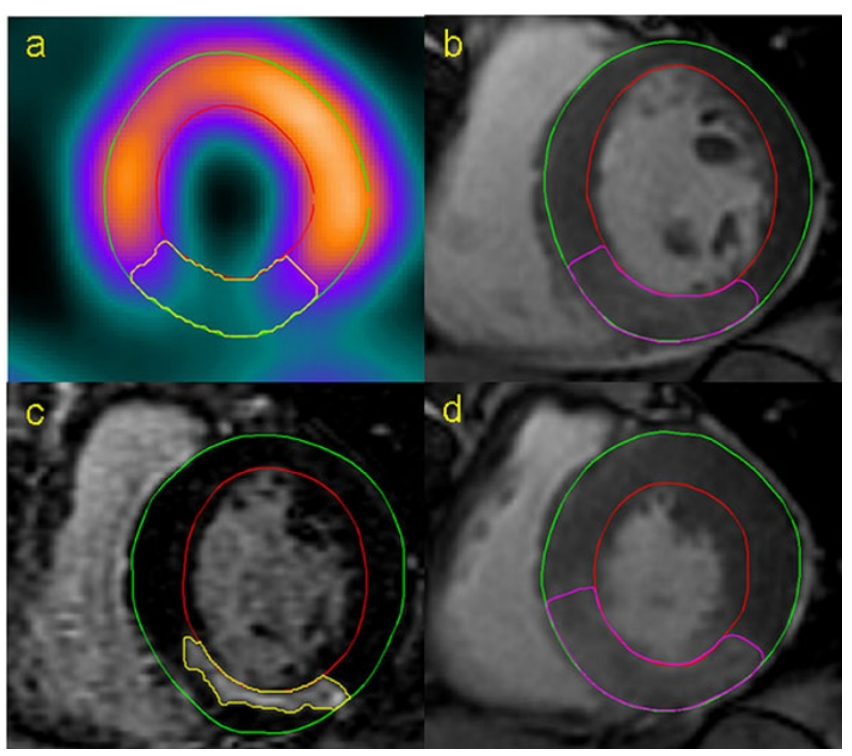

Figure 2

Publish with Bio Med Central and every scientist can read your work free of charge

"BioMed Central will be the most significant development for disseminating the results of biomedical research in our lifetime."

Sir Paul Nurse, Cancer Research UK

Your research papers will be:

- available free of charge to the entire biomedical community

- peer reviewed and published immediately upon acceptance

- cited in PubMed and archived on PubMed Central

- yours - you keep the copyright 